\title{
Managing Stakeholder Expectations in a Politically Polarized Society: An Expectation Violation Theory Approach
}

\author{
Aimei Yang, ${ }^{1}$ () Adam Saffer, ${ }^{2}$ () and Yiqi Li ${ }^{1}$
}

1. Annenberg School for Communication and Journalism, University of Southern California, 3502 Watt Way \#304, Los Angeles, CA,USA

2. University of Minnesota-Twin Cities, Hubbard School of Journalism \& Mass Communication, 111 Murphy Hall, 206 Church St SE, Minneapolis, MN, USA

\begin{abstract}
In a polarized society, organizations are increasingly forced to take sides on controversial corporate social responsibility (CSR) issues. In recent years organizations have been challenged for their wrongdoings, inactions, or misinterpretations of societal expectations, which have drawn questions about their CSR efforts. The current study draws upon expectation violation theory to examine how stakeholders' expectations for an organization's CSR efforts and their observed accountability for those CSR efforts influence two aspects of expectancy violations-violation importance and violation expectedness-while controlling for stakeholders' perceived reputation of an organization and political ideologies. Survey findings indicate that stakeholders' perceptions of an organization's reputation and accountability indeed lead to favorable evaluations of an organization's crisis response. Furthermore, the effect of stakeholders' expectations for an organization's CSR efforts is moderated by stakeholders political ideologies. These findings broaden expectation violation theory to include new variables in the context of CSR efforts that become closely associated with political issues.
\end{abstract}

KEYWORDS: CSR, social-mediated crisis, stakeholder relationship management, cancel culture

CONTACT Aimei Yang (D) • Email: aimei.yang@usc.edu • Annenberg School for Communication and Journalism, University of Southern California, 3502 Watt Way \#304, Los Angeles, CA 90089, USA 
As governments around the globe are fraught with political gridlock, stakeholders are increasingly turning to corporations to address pressing social and political issues. Subsequently, corporations are challenged with staying abreast of stakeholders' expectations for their involvement in social and political issues. The global refugee and immigration crisis is an example where stakeholders are expecting corporations and other institutions to act (De Zúñiga et al., 2014). Indeed, a corporation's planned involvement in such an issue typically falls under the purview of corporate social responsibility (CSR); yet, corporations can also become inadvertently involved in such issues when their actions are perceived as being associated with an issue. If those actions violate stakeholders' expectations, a crisis may ensue. Yet, we know little about how stakeholders' expectations interact in the context of an organizational crisis.

This study contributes to the literature by examining how stakeholders' evaluations of a corporation's involvement in an issue are influenced by their expectations. Rather than studying stakeholders' attribution of blame or how a crisis threatens a corporation's reputation, our focus is on stakeholders' expectations. Drawing from expectation violation theory (Burgoon, 1993), we construct a framework to understand how stakeholders' CSR expectations influence their evaluations of a corporation's response to violations of their expectations. We consider, as other studies suggest, that a corporation's reputation and perceived accountability for its actions can interact and influence how stakeholders evaluate the corporation's crisis response. Additionally, we recognize that CSR issues are often politicized, especially in the U.S. Thus, we examine how stakeholders' political ideology influence their evaluations of a corporation's crisis response.

This study begins by drawing on crisis communication scholars' theorizing about the complexities of challenge crises (Coombs \& Holladay, 2002). This review presents the need to further consider stakeholders' expectations, specifically their CSR expectations, in challenge crisis research. We then turn to expectation violation theory (EVT) as a framework for such consideration and propose a set of hypotheses to investigate how stakeholders' CSR expectations, a corporation's reputation, stakeholders' perceived 
accountability for a corporation's actions, and stakeholders' political ideology interact in ways that impact their crisis response evaluations. The hypotheses are then tested using survey data from a national sample, and results and implications for theory and practice are discussed.

\section{Stakeholders, Crises, CSR, and Expectations}

Freeman (1984) defined stakeholders as "any group or individual who can affect or is affected by the achievement of the firm's objectives" (p. 53). Stakeholder theorists have long maintained the view that corporations need to effectively manage the demands of external stakeholders such as consumers, community activists, advocacy groups, religious organizations, and NGOs, while emphasizing the demands of internal stakeholders such as shareholders and employees (Freeman, 1984). Accordingly, Freeman argued that a corporation's success depends on its capacity to negotiate, balance, and satisfy the expectations of internal and external stakeholders. When a corporation does not satisfy those expectations, a crisis can ensue.

\section{Crises and Challenge Crises}

All corporations are threatened by the potential of a crisis that can range in its type and severity (Coombs, 2012). A crisis is the "perception of an unpredictable event that threatens important expectancies of stakeholders and can seriously impact an organization's performance and generate negative outcomes" (Coombs, 2012, pp. 2-3). Crises often involve a series of rapidly evolving incidents that bring about negative emotions and stresses affecting various stakeholders.

Coombs and Holladay (2002) identified 13 types of crises. Among them, a "challenge crisis" originates from "confrontations by disgruntled stakeholders claiming an organization is operating in an inappropriate manner" (p. 170). Unlike other crisis types, a challenge crisis is not caused by an event; rather, stakeholders' claims about a corporation's socially irresponsible or immoral behavior may instigate a challenge crisis (Coombs \& Holladay, 2015). Challenge crises have been discussed in relation 
to paracrisis, which refers to "a publicly visible crisis threat that charges an organization with irresponsible or unethical behavior" (Coombs \& Holladay, 2012, p. 409). A mismanaged paracrisis can escalate into a full-blown challenge crisis.

\section{Challenge Crises and CSR}

A corporation can experience a challenge crisis when it violates stakeholders' CSR expectations for an issue. A corporation's CSR efforts are the set of actions that aim to further social good, beyond the explicit pecuniary interests of corporations (Carroll, 1999). Corporations engage in CSR to proactively or reactively respond to stakeholders' concerns and demands in order to function sustainably in contemporary society. CSR communication is a communication strategy that allows organizations to respond to changes in the turbulent business environment, such as changing stakeholder CSR expectations, societal standards, and media attention. When conceptualized in this light, CSR communication can be understood as a dialogue between corporations and stakeholders that is not static, routinized organizational communication (Eisenegger \& Schranz, 2011).

Stakeholders' expectations are beliefs of what they expect and can profoundly influence decisions. CSR expectations are stakeholders' beliefs of how much responsibility corporations have on different social issues. That is, "when CSR becomes integrated into the corporate reputation and become a public expectation, perceptions of social irresponsibility become a reputational threat" (Coombs \& Holladay, 2015, p. 145). Stakeholders who claim a social grievance against a corporation may challenge a corporation's social performance because their CSR expectations were violated.

A key trigger of challenge crises is the mismatch between corporations' policies, strategies, and actions, as well as stakeholders' expectations for socially responsible behaviors. Zhao and associates' (2014) analysis of 309 publicized crises found that, for decades, multinational corporations have taken advantage of developing countries' flawed institutional systems and low CSR expectations, and applied CSR standards that are lower than standards 
in developed countries. These corporations have profited through such practices without drawing much criticism because their CSR practice was consistent with stakeholders' expectations.

Indeed, in different countries, stakeholders prioritize different issues or aspects of issues. For instance, Zhao et al. (2014) showed that a mismatch between corporations' outdated CSR standards and stakeholders' expectations can trigger challenge crises. Golob and Bartlett (2007) compared CSR reports from Australian and Slovenian corporations and found considerable differences in what social issues stakeholders and organizations chose to prioritize. Similarly, D. Kim et al. (2010) found that "climate change" is a key concern in Europe and North America, while stakeholders in Asian countries tend to be concerned about "resources/waste management." Nonetheless, with new social monitoring mechanisms and raising consumers' CSR expectations in emerging markets, companies are increasingly faced with challenge crises.

Still, as Freeman (1984) claimed, organizations depend on stakeholders for survival. Therefore, an important goal of an organization's crisis communication efforts is to effectively communicate with stakeholders and ensure their positive evaluation of the organization's crisis response and reputation. By knowing the extent to which stakeholders attribute the crisis to an organization, communicators can employ the appropriate response strategies for assuaging reputational threat or bolstering their organization's crisis response strategy. Yet, there is more to understand about crises than stakeholders' attributions. Previous studies suggest that stakeholders' expectations are significant factors that influence how stakeholders evaluate a crisis (S. Kim, 2014). S. Kim found that stakeholder expectations and stakeholders' OPR relational satisfaction level predict the valence of their negative responses to organizations in crisis. While previous research has discussed expectations, few have made it the focus.

We assert that crisis communication needs a more complete understanding of stakeholders' expectations. Given the connection between a crisis and the violation of stakeholder expectations, this study draws on expectation violation theory to understand how stakeholders' expectations influence their evaluation of corporate crisis responses. 


\section{Expectation Violation Theory and Stakeholder Expectations}

Businesses operate in complex social and political environments and must consider a variety of stakeholders' expectations. Expectation violations theory offers a framework to begin to more fully understand the role of stakeholders' expectations in crises.

\section{Expectation Violation Theory}

Expectancy Violations Theory (EVT) was developed to understand and predict how individuals may respond to unexpected behaviors (Burgoon, 1993). The theory begins by defining expectations as "an enduring pattern of anticipated behavior" (Burgoon, 1993, p. 31). EVT argues that individuals' behaviors are guided by norms and values, which we expect others to follow. An expectation violation can cause cognitive arousal that help individuals to cope with others' unexpected behaviors (Afifi \& Metts, 1998). EVT specifies that when an expectation violation occurs, individuals may first give greater attention to the unexpected behavior. Individuals then process and cope with the expectation violation through an interpretation and evaluation stage. This evaluation stage helps individuals to understand the nature of transgression and how to proceed with future behaviors.

Applied to this study, the same norms and values that guide one's socially responsible behaviors are also the norms and values that one would expect corporations to follow. However, when a behavior differs from what is expected, an expectation violation occurs. In an incident that involves violations of CSR values, stakeholders may first pay attention to the unexpected corporate behaviors then evaluate the transgressing corporations. Importantly, this conceptualization positions the violation of stakeholders' expectations as the impetus for a crisis.

While EVT began in the field of interpersonal communication, the theory has been applied in a number of communication fields including computer-mediated communication and public relations (Bevan et al., 2014; Olkkonen \& Luoma-aho, 2015). Dewan and Jensen (2019) applied EVT to examine how a scandal shapes the effect of social status in labeling of an alleged violation of rules and norms. The study found that organizational status is likely to 
be a liability rather than an asset when alleged violation is part of a more widespread scandal.

EVT holds the potential to offer great insights for crisis communication because, as noted above, previous crisis research has widely identified expectation violation as a critical component (Zhao et al., 2014). EVT helps to specify the types of expectation violations and other related factors. This framework helps to examine expectation violation-related issues and can be valuable for social expectation-related crises such as CSR-related challenge crises.

Afifi and Metts (1998) extended EVT by introducing three dimensions of expectation violations. First, violation valence refers to the extent to which a behavior is seen as positive or negative. A negative violation is an unfavorable event that is not consistent with social norms or past interactions. In contrast, a positive violation refers to behaviors that exceeded expectations. A positive violation is a communication occurrence that is viewed favorably, even more so than mere conformity of expectations. Second, violation expectedness, which refers to the magnitude the behavior differs from the range of expected behaviors. For instance, in the context of computer-mediated communication, Bevan et al. (2014) found that when users are unfriended on Facebook, users assessed the magnitude of the violations based on the closeness, importance, and length of the friendship, but also by the behaviors of how the unfriender used Facebook. A negative violation with a high magnitude may be especially detrimental to relationships and lead to unfavorable evaluations. Finally, violation importance turns the focus to the relational aspects of a violation by considering the importance of the relationships and the impact that the violation will have on the relationship between the violator and violated. Next, we use EVT to extend our understanding of stakeholders' evaluations of corporate responses.

\section{Applying EVT to Stakeholders' Expectations in a Challenge Crisis}

The three concepts identified by Afifi and Metts (1998) help to explain the extent to which stakeholders may negatively evaluate 
a corporation's crisis response. Provided that organizations in a crisis would only find themselves challenged by stakeholders with violated expectations, this study does not examine violation valence. Instead, we focus on variables that may affect stakeholders' violation importance and violation expectedness. We assert that stakeholders' perceptions of a corporation's reputation and accountability can be understood as manifestations of violation expectedness and stakeholders' CSR expectations and political ideologies to be proxies of violation importance.

Violation expectedness and reputation. EVT suggests that individuals' expectations for how others will behave is guided by their certainty others will follow a set of norms and values. Violation expectedness captures the degree to which one's behavior is counter to the anticipated behavior (Olkkonen \& Luoma-Aho, 2015). When one is highly certain of another's behavior but the other does not actually meet those expectations, the magnitude of the violation expectedness is increased.

Stakeholders set expectations for how an organization will behave based on an organization's reputation. Reputation can be understood as an estimate or evaluation that stakeholders have about an organization's behaviors. A firm's reputation gives stakeholders some certainty for how likely it will follow a set of norms and values. Violations of expected organizational behaviors can adversely affect relationship quality by increasing uncertainty of what to expect in the future (Bevan et al., 2014).

In the context of organizational crisis, reputation is the concept that is most frequently associated with stakeholders' expectations (Olkkonen \& Luoma-aho, 2015). Reputation influences stakeholders' evaluations of an organization's crisis response. Organizations with prior negative reputations are usually more often blamed with greater crisis responsibility for the same crisis in comparison to an unknown organization or an organization with a positive reputation (Coombs \& Holladay, 2012). This is likely because stakeholders with negative organizational reputation assessments have more uncertainty about an organization. In other words, transgressing behaviors from corporations with bad reputations are more likely to be considered as "behaviors that signal a lack of confidence in 
the viability of the relationship, cause relational trauma or lead directly to the termination of the relationship" (Afifi \& Metts, 1998, p. 377). Based on EVT and previous crisis communication literature, it is reasonable to predict:

Hypothesis 1: Stakeholders' perception of an organization's reputation positively influences their evaluation of the organization's crisis response.

Violation expectedness and perceived accountability. Accountability refers to the implicit or explicit expectation that organizations who fail to provide a satisfactory justification for their actions will suffer negative consequences (Brennan \& Solomon, 2008). Whereas uncertainty about the future may adversely influence perceptions about the corporation's reputation, knowing that the corporation is being held accountable may offer stakeholders' certainty about the future. In other words, it is possible that accountability mitigates expectation violations by increasing the certainty stakeholders have about a corporation's future behaviors.

While accountability has roots in accounting and management (Brennan \& Solomon, 2008), CSR scholars have either narrowly considered accountability as being accountable to shareholders or have conflated the term with transparency. On one hand, scholars have recognized the importance of corporate accountability to a wide range of stakeholders (Brennan \& Solomon, 2008). Lim and Greenwood (2017) argued that "stakeholder engagement in the process of CSR communications is the best way to ensure accountability" (p. 774). On the other hand, some CSR scholars have assumed accountability derives from transparency (Bachmann et al., 2015). Yet transparency refers to "the disclosure of relevant information about the organization's decision-making processes, procedures, functioning and performance to stakeholders and the wider public" (Bachman et al., 2015, p. 1133). Accountability goes beyond mere transparency, and implies that a corporation is being held responsible for its actions.

We assert that when stakeholders perceive that a corporation is being held responsible for its actions, whether that is from stakeholders or society in general, that reduces stakeholders' uncertainty for future behaviors. During crises, corporations that demonstrate 
a capacity to engage stakeholders, be held responsible for their mistakes or violation of acceptable behavior, and are willing to take actions, may be seen as being accountable. Especially during crises, being accountable or acting in accountable ways may be an important mechanism to mitigate stakeholders' uncertainty. In other words, informed by EVT, accountability could reduce the uncertainty in violation expectedness and, therefore, lead to more favorable evaluation of corporate behaviors:

Hypothesis 2: Stakeholders' perception about an organization's accountability positively influences their evaluation about the organization's crisis response.

Violation importance and CSR expectations. Afifi and Metts (1998) argued that violations also differ in the degree to which the violations are considered important by the various stakeholders. They recognized that not all stakeholders assign the same level of importance to all violations. In the context of CSR, some stakeholders may not find a particular CSR issue (i.e., sustainable supply change) as important; therefore, an expectation violation would not produce a strong reaction. Yet, it is necessary to recognize that many CSR stakeholders may actually be issue publics, who "may not have mastery over a wide range of political issues but rather are specialists who are passionately concerned with particular issues on the basis of their values, identities, and interest" (Y. M. Kim, 2009, p. 255). If a stakeholder considers certain CSR issues (e.g., animal rights, gender equality, etc.) important, it is likely a corporate violation in these areas would produce strong reactions from this stakeholder. Drawing from EVT's conceptualization of violation importance, we posit that greater stakeholder importance of a CSR issue will negatively influence stakeholders' evaluations of the transgressing corporation's crisis response.

Hypothesis 3: Stakeholders' importance of a CSR issue will be negatively related to stakeholders' evaluation of the transgressing organization's crisis responses.

Violation importance and the moderating role of political ideology. Political ideology refers to a set of political beliefs about the 
proper order of society and how it can be achieved (Feldman \& Johnston, 2014). Political consumerism refers to the act of making purchase decisions based on ethical or political considerations. Through political consumerism, stakeholders can express their political ideologies and engage in lifestyle-oriented politics. For instance, stakeholders' perceptions of companies' CSRrelated misconduct often leads to political consumerism actions (De Zúñiga et al., 2014). Additionally, people with different political ideologies may form different evaluation about issues.

In other words, we believe political ideology may affect stakeholders' perceptions of violation importance. EVT maintains that what counts for expected norms and values differ from person to person (Afifi \& Metts, 1998). Among different values and norms, stakeholders' political ideology may be a strong influence on evaluations about politicalized issues. Also, CSR issues often can be politicalized (Scherer \& Palazzo, 2011). As CSR issues become politicalized, one factor that may exert a considerable moderating effect on stakeholders' CSR expectations is stakeholders' political ideologies. Political ideologies serve the function to describe or interpret the world "by making assertions or assumptions about human nature, historical events, present realities, and future possibilities" and "to envision the world as it should be, specifying acceptable means of attaining social, economic, and political ideals" (Jost et al., 2009, p. 309).

In other words, when it comes to specific CSR issue areas, people with different ideology may have different violation expectedness (Afifi \& Metts, 1998).

Hypothesis 4: Stakeholders' political ideology moderates the relationship between stakeholders' CSR expectation and stakeholders' evaluation of an organization's crisis response.

To summarize the conceptual model guiding this study (see Figure 1), violation importance, or how important do stakeholders believe the transgression is, can be understood operationally by measuring stakeholders' CSR expectations and political ideology; whereas violation expectedness, or to what degree stakeholders expect the transgression to happen, can be observed through stakeholders' perceived accountability and reputation. 


\section{FIGURE 1 The Hypothesized Model}

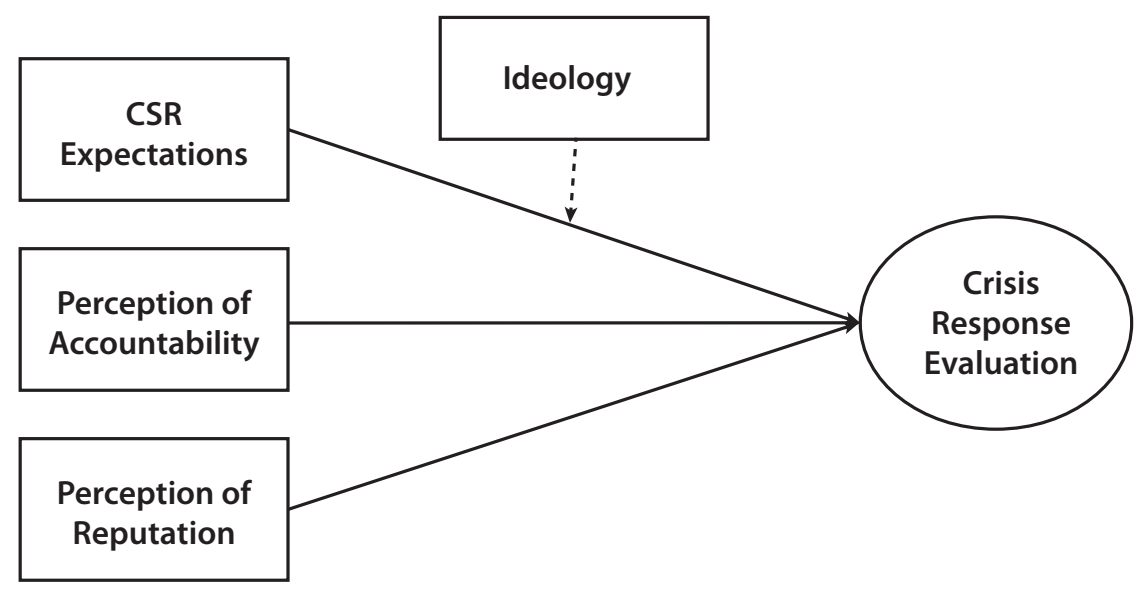

\section{Case Description}

On January 28, 2017, after President Donald Trump announced an executive order banning travelers from seven Muslim-majority countries, the New York Workers Alliance called out to their taxi drivers to avoid the John F. Kennedy Airport (JFK Airport) for an hour, as an act to stand against the travel ban. Around the same time, Uber announced on Twitter that it canceled its price surge around the JFK Airport, which is a feature that increases ride costs at a time of high demand. The act soon received backlash from angry social media users. Uber was accused of profiting from the protest. A Twitter hashtag \#deleteuber broke out calling for customers to boycott Uber (Isaac, 2017). People started posting screenshots on their social media accounts of deleting their Uber accounts, and many celebrities like Janelle Monáe, Taraji P. Henson, Jesse Tyler Ferguson, and George Takei also joined in the online protest against Uber. According to the New York Times (Isaac, 2017), at least 200,000 accounts were deleted.

Uber immediately responded by stating their intentions were only to serve their customers and they were misunderstood by the public. Uber CEO Travis Kalanick also came out against the travel ban by calling it "unjust" on his Facebook page and announced 
that the company will contribute $\$ 3$ million to help their drivers affected by the immigration ban and provide them with $24 / 7$ legal assistance. However, those acts did not appease the social media consumer activism when some called out that Kalanick was actually sitting on Trump's advisory committee. Kalanick stepped down from Trump's council one week later (Isaac, 2017).

\section{Method}

\section{Sample and Procedure}

Upon the approval of the Institutional Review Board (IRB), an online survey was conducted via the research firm Survey Sampling International (SSI) via (http://www.surveysampling.com) in May 2017. SSI provides access to millions of Internet users from diverse demographic backgrounds who voluntarily participate in online studies for various rewards offered by SSI. To achieve a representative sample, we instructed SSI to use random sampling strategies to solicit respondents, and received 1,060 completed responses (average completion time $=21 \mathrm{~min}$ ). Before participants started the survey, they read a news story about the \#deleteUber incident. An attention check question was placed immediately after the story to ask which company made a donation to the American Civil Liberties Union. Participants with wrong answers were directed toward the end of the survey. This step is taken to ensure participants were fully aware of the incident and has the information to assess Uber's crisis response. In the end, there were 687 valid questionnaires.

The participants' average age was 44.92 (SD = 17.11). Further, $44.3 \%$ of participants were males, $55.3 \%$ were female, and $3 \%$ indicated being gender fluid. Most participants had either a high school (37.8\%) or bachelor's (32.5\%) degree. Participants' median income was reported as $\$ 40,000$ to $\$ 59,000$. This sample closely resembles that of the 2010 U.S. census data.

\section{Measures}

Table 1 reports the basic statistics for all independent variables. 
TABLE 1 Means, Standard Deviations, and Correlations for Independent Variables

\begin{tabular}{|l|c|c|c|c|c|c|}
\hline & $\mathbf{M}$ & SD & $\mathbf{1}$ & $\mathbf{2}$ & $\mathbf{3}$ & $\mathbf{4}$ \\
\hline $\begin{array}{l}\text { 1. Refugee/Immigrant } \\
\text { CSR Expectations }\end{array}$ & 3.858 & 1.630 & - & - & - & - \\
\hline 2. Ideology & 3.738 & 1.670 & $.349^{* *}$ & - & - & - \\
\hline 3. Uber Accountability & 4.235 & 1.732 & $.107^{* *}$ & $.192^{* *}$ & - & - \\
\hline $\begin{array}{l}\text { 4. Perception of } \\
\text { Uber's Reputation }\end{array}$ & 4.018 & 1.318 & $.206^{* *}$ & $.239^{* *}$ & $.305^{* *}$ & - \\
\hline${ }^{*} p<.05,{ }^{* *} p<.01{ }^{* * *} p<.001$ & & \\
\hline
\end{tabular}

Perception of Uber's reputation. Following Huang et al. (2014), we asked participants to indicate the degree (7-point scale) to which they agree with four statements such as "I have a better impression of Uber" and "I think Uber has a good overall image." The four items were combined into one variable (Cronbach's $\alpha=$ $.905 ; \mathrm{M}=4.018, \mathrm{SD}=1.318)$.

Immigrant/refugee related CSR expectations. To measure this variable, we asked four questions on a 7-point scale such as "Do you think companies should make an effort to support immigrants or refugees" and "Companies should donate part of their products and services to support immigrants or refugees." The four items were combined into one variable (Cronbach's $\alpha=.954 ; \mathrm{M}=3.858$, $\mathrm{SD}=1.630$ ).

Perception of Uber's accountability. Without any known established measure of accountability, we used a single item to assess stakeholders' perception about Uber's accountability on the company's action during the incident on a 7-point bi-polar scale (accountable-unaccountable). This variable is reverse coded $(\mathrm{M}=4.235, \mathrm{SD}=1.732)$.

Political ideology. Participants' ideologies were assessed by asking them to rate themselves on a 7 -point scale $(1=$ very liberal; $7=$ very conservative $)$ in terms of economic $(M=3.849$, $\mathrm{SD}=1.750)$ and social issues $(\mathrm{M}=3.638, \mathrm{SD}=1.763)$. The two 
items were combined into one variable (Cronbach's $\alpha=.897$; $\mathrm{M}=3.738, \mathrm{SD}=1.670$ ).

Stakeholders' overall evaluation of Uber's crisis response. This is the dependent and latent variable and two sets of measures were used: perception of Uber's crisis responsibility and evaluation of Uber's crisis response strategies. These two set of measures capture different dimensions of stakeholders' evaluation of crisis response. First, to assess participants' perception of Uber's crisis responsibility, we asked participants to indicate how much responsibility Uber bears on a 7-point bipolar scale. This included two items: "not at all responsible" to "totally responsible" and "not at all to be blamed" to "absolutely to be blamed." The two items were combined into one variable (Cronbach's $\alpha=.887 ; \mathrm{M}=4.112$, $\mathrm{SD}=1.714)$. Further, following H. J. Kim and Cameron (2011), we asked participants to indicate their impression about the organization's response strategies to the incident on a 7-point bipolar scale that include the following six items (see Figure 2 for items 1 to 6 ): sincere-insincere, trustworthy-untrustworthy, honest-dishonest, believable-unbelievable, experienced-inexperienced, and expert-not expert. In order to identify the most relevant items, exploratory factor analysis was conducted.

In the hypothesized model, evaluation about Uber's response strategies and responsibility level were used to indicate stakeholders' overall evaluation of Uber's crisis response.

\section{Data Analysis}

Structural equation modeling, with maximum likelihood method of estimation, was implemented with the Lavaan program in $\mathrm{R}$. The analysis took two steps. The first step considers the factor structure of stakeholders' crisis evaluation. Confirmatory factor analyses were implemented to validate the multidimensional measurement of this latent variable. The second step involves a comprehensive model that includes all variables. Model fit indices specify whether the difference between the observed and the reproduced covariance matrices are due to chance. This study relies on comparative fit index (CFI) and the root mean square error of approximation 
(RMSEA) to assess model fit. This is because a method such as $\chi^{2}$ is very sensitive to sample size (Keith, 2014). A small difference between a hypothesized model and sample data can result in exponential increase in the $\chi^{2}$ statistics. Given the sample size of the current study, it is more appropriate to use other fit indicators.

\section{Results}

The comprehensive model (see Figure 2 and Table 2) has a good model fit $(\mathrm{CFI}=.941$ and RMSEA $=.069)$. Very good model fit is indicated by a CFI of .95 or higher and an RMSEA of .08 or less (Keith, 2014). Thus, the hypothesized model is tenable with the data used in this study. In the estimated model (see Figure 2), stakeholders' perception about Uber's reputation positively influences their evaluation about Uber's crisis response $(\beta=.394$, $p<.001)$, and hypothesis 1 was supported. Further, stakeholders' expectations about Uber's accountability positively influences their evaluation about Uber's crisis response $(\beta=.497, p<.001)$; thus, hypothesis 2 was supported.

\section{FIGURE 2 The Fitted Model}

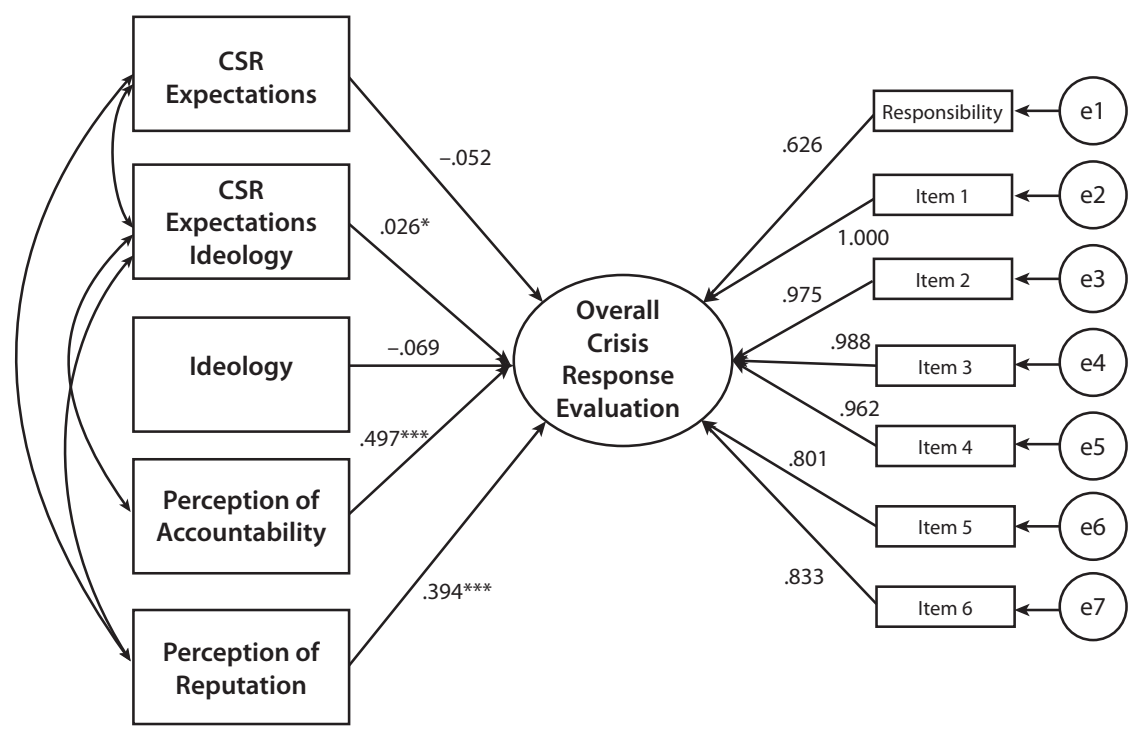

Chi-Square $=318.072$ 
Table 2 Fit Indexes for Models

\begin{tabular}{|l|c|c|c|c|c|c|}
\hline Models & $\mathbf{X}^{2}$ & $\mathbf{d f}$ & RMSEA & CFI & $\boldsymbol{\delta} \mathbf{X}^{2}$ & $\boldsymbol{\delta}$ df \\
\hline $\begin{array}{l}\text { Model 1 } \\
\text { (With Interaction effect) }\end{array}$ & 318.072 & 44 & .069 & .941 & & \\
\hline $\begin{array}{l}\text { Model 2 (Without } \\
\text { Interaction effect) }\end{array}$ & 292.002 & 38 & .103 & .945 & & \\
\hline $\begin{array}{l}\text { Difference between } \\
\text { Model 1 and 2 }\end{array}$ & & & & & $26.070^{* * *}$ & 6 \\
\hline${ }^{*} p<.05,{ }^{* *} p<.01,{ }^{* * *} p<.001$ & & & \\
\hline
\end{tabular}

In the fitted model, there is no significant relationship between stakeholders' CSR expectations and the refugee/immigrant issue and their evaluation of Uber's crisis response $(\beta=.069, p=$ n.s.), and no significant relationship between political ideology and stakeholder's crisis evaluation $(\beta=.052, p=$ n.s.). However, the interaction effect between stakeholders' political ideology and CSR expectations produced significant results $(\beta=0.026, p<.05)$, suggesting a moderation effect. Overall, more liberal stakeholders tend to evaluate Uber's response lower (mean $=3.968$ ) whereas more conservative stakeholders tend to evaluate Uber's response higher $($ mean $=4.364)$. To further test the moderation effect, we examined if the two variables significantly influence the dependent variable without the moderation effect. As such, we fitted Model 2 without the interaction effect. The comparison of model fit between Model 1 (with interaction effect) and Model 2 (without interaction effect) can be found in Table 2. Model 2 did not achieve a good fit $\left(\chi^{2}=292.002, d f=38, p<.00\right.$; CFI $=.945$; RMSEA $=$ .103). Notably, without the interaction effect (Model 2), stakeholders' CSR expectations $(\beta=.05, p<.05)$ and political ideology $(\beta=.03, p<.05)$ significantly influence stakeholders' evaluations of Uber's crisis response, which further confirms a strong moderation effect as predicted in hypothesis 4 . This is because the effect of a moderating variable is statistically demonstrated through interaction. While Model 2 showed that the two variables are significant, the inclusion of the interaction affected the strength of these two variables on the dependent variable. As such, we conclude that hypothesis 3 is partially supported and hypothesis 4 is supported. 


\section{Discussion}

The \#deleteUber crisis is not a one-off incident. In fact, we suspect organizations will increasingly find themselves in the midst of similar crises in the years to come. As wicked issues continue to plague societies and as governments struggle with political gridlock and rising populism (Head \& Alford, 2015), citizens around the world will continue to expect corporations to play prominent roles in addressing social issues.

\section{Exploring the Complexities of Crises}

A crisis could arise from a corporation's CSR wrongdoings or inactions that violate stakeholders' expectations of norms and values, or social and political obligations (Coombs \& Holladay, 2015). Prior research has primarily studied whether CSR is a reputational asset or liability during crises (Coombs \& Holladay, 2015). Our study takes one step further and examines how reputation and other variables interact to influence stakeholders' evaluations of corporate crisis responses. Taking a stakeholder perspective, we applied expectation violation theory (Burgoon, 1993) and, more specifically, Afifi and Metts's (1998) dimensions of expectation violations-violation valance, violation expectedness, and violation importance-to explore the factors that influence stakeholders' evaluations of a corporation's crisis responses. Prior crisis communication research suggests stakeholders' expectations in a crisis inherently produces a negatively valanced condition. Our conceptual model thus focused on the latter two expectation violation dimensions. The model posits that stakeholders' perceptions of an organization's reputation and accountability impact their violation expectedness and stakeholders' CSR expectations on issues. Further, political ideologies influence stakeholders' perceptions of violation importance. Conceptually, our model suggests that violation expectedness and violation importance affect stakeholders' evaluations of a corporation's crisis response. Our data provide empirical evidence to lend support to this model. 


\section{Applying Expectation Violation Theory to Crisis Communication}

Violation importance. This study postulated that stakeholders' CSR expectations may influence stakeholders' evaluations by influencing the violation importance. Violation importance, which accounts for the impact that the violation will have on the relationship between the violator and violated (Afifi \& Metts, 1998), was assessed by considering stakeholders CSR expectations and political ideologies. The empirical evidence for this hypothesis is less straightforward in the sense that the effect of CSR expectations is moderated by stakeholders' political ideologies. We drew upon EVT and the often-politicalized nature of crises (Scherer \& Palazzo, 2011), to suggest that it is likely that stakeholders with liberal and conservative ideologies may embrace different CSR values and thus assign different levels of violation importance to a CSR violation. In other words, what counts as a CSR violation or serious violation may differ along the political ideological fault line. As expected, we found that stakeholders' CSR expectations influence their evaluations of an organization's crisis response and are significantly moderated by their political ideologies.

Given the current political climate, it is likely that more organizations will be challenged by crises that derive from politicized social issues. We did not focus on the ways organizations should handle political issues, but we sought to explore the impact stakeholder's political ideologies might have on their CSR expectations and evaluations of an organization's crisis responses. We found that the price for violating CSR expectations is daunting. Even Uber's former CEO recognized this when he commented on the high price the company has to pay for failing to meet CSR expectations (Isaac, 2017). Based on this finding, we believe that scholars and communication managers should not merely focus on the impact stakeholders' political ideologies have on CSR expectations, evaluations of crisis responses, or an organization's reputation; rather we believe there is a more pressing need to direct attention toward the ways corporations can effectively address the social issues that are the sources of crises. 
Indeed, the short-term effects of a crisis may be detrimental to a corporation's reputation, but crises may force corporations to become attuned to stakeholders' expectations or even directly address social issues. Looking at the long term and broader effects, we believe that crises may bring corporations to engage in broad conversations with society and step up to take on more social responsibility. As such, understanding the mechanisms of crises may help prepare organizations for tough challenges ahead and benefit society at large. As corporations navigate this uncharted territory, these crises may motivate corporations to understand and engage with their stakeholders in more dialogic and sophisticated ways. In addition to the theoretical values already discussed, this study has practical implications for communication managers that we discuss in the following section.

\section{Implications}

Organizations should better communicate their CSR efforts. Traditionally, corporations have taken a responsive approach to promote their social responsibility (Brennan \& Solomon, 2008). Our findings invite us to reconsider the validity of traditional, one-way communication strategies that treat stakeholders merely as consumers of an organization's CSR efforts or crisis responses. Instead, our data suggest that to effectively manage crises, communication managers need to actively engage stakeholders, understand stakeholders' CSR expectations, their political ideologies, and proactively manage CSR issues. We believe that a stakeholder engagement approach to CSR offers corporations, as well as stakeholders, numerous opportunities during a crisis.

First, a stakeholder engagement approach can create the means for communication managers to understand their stakeholders' CSR expectations and political ideologies (De Zúñiga et al., 2014). It is advisable for practitioners to research and understand stakeholders; however, the standard ways corporations research stakeholders do not provide opportunities to understand stakeholders in meaningful ways or allow for a dialogue to occur. A stakeholder engagement approach calls on corporations to regularly and actively incorporate stakeholders into a corporation's 
decision-making processes. Understandably, the capacity to enact such recommendation is formidable at first glance; however, we ask communication managers to juxtapose the seemingly daunting task of engaging stakeholders against the threats posed by a crisis. We argue that a stakeholder engagement approach can better position practitioners to understand the intricacies of stakeholders' CSR expectations and political ideologies than traditional approaches to CSR.

Second, corporations should demonstrate their accountability during crises. Our data suggest that when stakeholders perceive a corporation as being accountable during a crisis, their evaluations of the corporation's crisis response is more positive. A stakeholder engagement approach offers an effective and authentic way for corporations to communicate and demonstrate their accountability. In fact, Lim and Greenwood (2017) found that corporations that engage stakeholders in CSR communication are more likely to be perceived as accountable and, therefore, better accomplish business goals. Future studies may look at if the extent and types of business engagement strategies during crises affect perceived corporate accountability.

\section{Limitations and Future Research}

Like all studies exploring a new area of the literature, there are some limitations to our findings. Namely, Uber as a company has long been faced with issues ranging from how they pay their drivers to safety concerns for passengers. As such, stakeholders' unfavorable evaluation of this company may have additional causes beyond the \#deleteuber crisis. However, we found that a real-life crisis scenario bolstered our study's external validity. Nevertheless, it should be noted that our sample size is relatively small. In comparison to experiments, our survey methods cannot fully control certain factors. Further, since we draw our sample and case from a U.S. context, findings may not be applicable to other countries.

Nonetheless, these findings demonstrate the value of EVT in the context of crisis and introduced new variables to the theory. Future studies may build upon the current research to comprehensively examine the application of EVT in crisis communication. 
We call on future researchers to test the model presented here with less well-known companies involved in crisis, and see what concepts stand out in terms of influence level. Finally, limited by the timing of our study, we know little about how organizations can renew after a crisis (Manzie, 2018). CSR crises are violations of stakeholders' expectations for the norms and values of a society (Coombs \& Holladay, 2002); thus, the renewal after a crisis may be unique. We believe that future studies can build from the foundation provided by the discourse of renewal literature to explore how corporations can re-establish reputations by meeting stakeholders' CSR expectations.

\section{Acknowledgment}

This project was supported by an internal grant provided by the Annenberg School for Communication and Journalism at the University of Southern California in 2016.

\section{ORCID}

Aimei Yang (1) https://orcid.org/oooo-0003-3756-7812 Adam Saffer (i) https://orcid.org/oooo-0001-8032-4256

\section{References}

Afifi, W. A., \& Metts, S. (1998). Characteristics and consequences of expectation violations in close relationships. Journal of Social and Personal Relationships, 15(3), 365-392. https://doi. org/10.1177/0265407598153004

Bachmann, R., Gillespie, N., \& Priem, R. (2015). Repairing trust in organizations and institutions: Toward a conceptual framework. Organization Studies, 36(9), 1123-1142. https://doi. org/10.1177/0170840615599334

Bevan, J. L., Ang, P. C., \& Fearns, J. B. (2014). Being unfriended on Facebook: An application of expectancy violation theory. Computers in Human Behavior, 33(1), 171-178. https://doi. org/10.1016/j.chb.2014.01.029 
Brennan, N. M., \& Solomon, J. (2008). Corporate governance, accountability and mechanisms of accountability: An overview. Accounting, Auditing \& Accountability Journal, 21(7), 885-906. https://doi.org/10.1108/09513570810907401

Burgoon, J. K. (1993). Interpersonal expectations, expectation violations, and emotional communication. Journal of Language and Social Psychology, 12, 30-48. https://doi. org/10.1177/0261927X93121003

Carroll, A. B. (1999). Corporate social responsibility: Evolution of a definitional construct. Business \& Society, 38(3), 268-295. https://doi.org/10.1177/000765039903800303

Coombs, W. T. (2012). Ongoing crisis communication: Planning, managing, and responding ( $3 \mathrm{rd} \mathrm{ed}$.). Sage.

Coombs, W. T., \& Holladay, S. J. (2002). Helping crisis managers protect reputational assets: Initial tests of the situational crisis communication theory. Management Communication Quarterly, 16(2), 165-186. https://doi.org/10.1177/089331802237233

Coombs, W. T., \& Holladay, S. J. (2012). The paracrisis: The challenges created by publicly managing crisis prevention. Public Relations Review, 38(3), 408-415. https://doi.org/10.1016/j. pubrev.2012.04.004

Coombs, W. T., \& Holladay, S. J. (2015). CSR as crisis risk: Expanding how we conceptualize the relationship. Corporate Communications: An International Journal, 2o(2), 144-162. https://doi.org/10.1108/CCIJ-10-2013-0078

Dewan, Y., \& Jensen, M. (2019). Catching the big fish: The role of scandals in making status a liability. Academy of Management Journal. https://doi.org/10.5465/amj.2018.0685

De Zúñiga, H. G., Copeland, L., \& Bimber, B. (2014). Political consumerism: Civic engagement and the social media connection. New Media \& Society, 16(3), 488-506. https://doi. org/10.1177/1461444813487960

Eisenegger, M., \& Schranz, M. (2011). Reputation management and corporate social responsibility. In $\varnothing$. Ihlen, J. L. Bartlett, and S. May (Eds.), The handbook of corporate social responsibility (pp. 128-146). John Wiley \& Sons, Inc. 
Feldman, S., \& Johnston, C. (2014). Understanding the determinants of political ideology: Implications of structural complexity. Political Psychology, 35(3), 337-358. https://doi. org/10.1111/pops.12055

Freeman, R. E. (1984). Strategic management: A stakeholder approach. Cambridge University Press. https://doi.org/10.1017/ cbo9781139192675.003

Golob, U., \& Bartlett, J. L. (2007). Communicating about corporate social responsibility: A comparative study of CSR reporting in Australia and Slovenia. Public Relations Review, 33, 1-9. https://doi.org/10.1016/j.pubrev.2006.11.001

Head, B. W., \& Alford, J. (2015). Wicked problems: Implications for public policy and management. Administration \& Society, 47(6), 711-739. https://doi.org/10.1177/0095399713481601

Huang, C. C., Yen, S. W., Liu, C. Y., \& Huang, P. C. (2014). The relationship among corporate social responsibility, service quality, corporate image and purchase intention. International Journal of Organizational Innovation (Online), 6(3), 68-84.

Isaac, M. (2017, January 31). What you need to know About \#DeleteUber. The New York Times. Archived at https://web. archive.org/web/20170209170430/https://www.nytimes. $\mathrm{com} / 2017 / 01 / 31 /$ business/delete-uber.html

Jost, J. T., Federico, C. M., \& Napier, J. L. (2009). Political ideology: Its structure, functions, and elective affinities. Annual Review of Psychology, 60, 307-337. https://doi.org/10.1146/annurev. psych.60.110707.163600

Keith, T. Z. (2014). Multiple regression and beyond: An introduction to multiple regression and structural equation modeling. Routledge.

Kim, D., Nam, Y., \& Kang, S. (2010). An analysis of corporate environmental responsibility on the global corporate Web sites and their dialogic principles. Public Relations Review, 36, 285-288. https://doi.org/10.1016/j.pubrev.2010.04.006

Kim, H. J., \& Cameron, G. T. (2011). Emotions matter in crisis: The role of anger and sadness in the publics' response to crisis news framing and corporate crisis response. Communication Research, 38(6), 826-855. https://doi. org/10.1177/0093650210385813 
Kim, S. (2014). The role of prior expectancies and relational satisfaction in crisis. Journalism \& Mass Communication Quarterly, 91(1), 139-158. https://doi.org/10.1177/1077699013514413

Kim, Y. M. (2009). Issue publics in the new information environment: Selectivity, domain specificity, and extremity. Communication Research, 36(2), 254-284. https://doi. org/10.1177/0093650208330253

Lim, J. S., \& Greenwood, C. A. (2017). Communicating corporate social responsibility (CSR): Stakeholder responsiveness and engagement strategy to achieve CSR goals. Public Relations Review, 43(4), 768-776. https://doi.org/10.1016/j. pubrev.2017.06.007

Manzie, V. D. (2018). Applying the rhetoric of renewal model in a contemporary African context: Lessons learned from the Royal Dutch Shell oil crisis in Nigeria. Journal of International Crisis of Risk Communication, 1(2), 201-224. https://doi. org/10.30658/jicrcr.1.2.2

Olkkonen, L., \& Luoma-Aho, V. L. (2015). Broadening the concept of expectations in public relations. Journal of Public Relations Research, 27(1), 81-99. https://doi.org/10.1080/106 2726X.2014.943761

Scherer, A. G., \& Palazzo, G. (2011). The new political role of business in a globalized world: A review of a new perspective on CSR and its implications for the firm, governance, and democracy. Journal of Management Studies, 48(4), 899-931. https:// doi.org/10.1111/j.1467-6486.2010.00950.x

Zhao, M., Tan, J., \& Park, S. H. (2014). From voids to sophistication: Institutional environment and MNC CSR crisis in emerging markets. Journal of Business Ethics, 122(4), 655-674. https://doi.org/10.1007/s10551-013-1751-x 

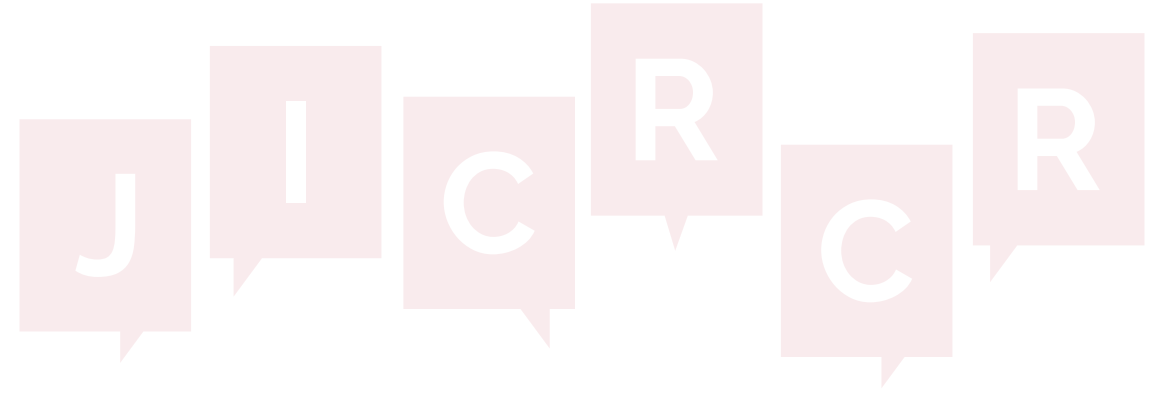